\title{
Comparison between Chinese and Japanese Social Media Requests
}

\author{
Wei Ren* \\ Professor, School of Foreign Languages, Beihang University, Beijing, China \\ weiren@buaa.edu.cn \\ Saeko Fukushima \\ Professor, Department of English, Tsuru University, Tsuru City, \\ Yamanashi, Japan \\ Hungarian Research Institute for Linguistics, Hungary \\ saeko@tsuru.ac.jp
}

\begin{abstract}
This study investigates Chinese and Japanese requests in social media communication, focusing on the requests made between university students. The data consisted of 300 social media requests made by 30 Chinese university students and 304 social media requests made by 30 Japanese university students, respectively. The findings revealed that the Chinese and Japanese participants displayed more similarities than differences regarding the request strategy that they preferred to use among peers on social media. Both groups employed direct requests the most frequently, followed by conventionally indirect requests. Non-conventionally indirect requests were used the least frequently by both groups. The Japanese participants employed twice as many external modifiers as their Chinese counterparts. In contrast, the Chinese participants used considerably more lexical/phrasal internal modifiers than the Japanese participants. The findings are discussed in relation to factors such as social distance, living arrangements and new technologies.
\end{abstract}

\section{Keywords}

requests - Chinese - Japanese - social media

* Corresponding author. 
Chinese and Japanese are two East Asian languages that are often investigated in pragmatics, partially because these two cultures are both fascinating and different from Western cultures in terms of politeness (Leech, 2007). Researchers have taken an interest in testing Brown and Levinson's (1987) politeness theory against data in the two languages (Chen, $\mathrm{He}$, and $\mathrm{Hu}, 2013$ ). Many studies have investigated various pragmatic practices in Chinese and Japanese and compared these two languages with English. Nevertheless, little research has compared speech act realisations in Chinese and Japanese.

The speech act of request is the most researched speech act in pragmatics, regardless of contrasting between different languages (e.g., Blum-Kulka, House, and Kasper, 1989; Fukushima, 2000; Chen et al., 2013; Ogiermann and Bella, 2020), within a pluricentric language (e.g., Barron, 2008; Ren, 2018b) or from the second language perspective (e.g., Woodfield and Economidou-Kogetsidis, 2012; Schauer, 2009). Previous studies have compared requests in Chinese and English (e.g., Yeung, 1997, 200o; Zhu, 2016) and compared requests in Japanese and English (e.g., Fukushima, 1996, 2000, 2003; Hill, Ide, Ikuta, Kawasaki, and Ogino, 1986; Rinnert and Kobayashi, 1999). In addition, Rue and Zhang (2008) investigated request strategies in Chinese and Korean. To the best of our knowledge, however, there are few comparative studies between requests in Chinese and Japanese (e.g., Chen et al. 2013).

Social media is a pervasive phenomenon of everyday life. Such digital communication is challenging many findings and theories in pragmatics research (Ren, 2018a) and thus has attracted much attention in the existing literature (Page, 2012; Tagg, Seargeant, and Brown, 2017; Bou-Franch and Garcés-Conejos Blitvich, 2019). This is partly because electronic corpora provide a rich, readily available source of authentic data that can offer a wide scope and rich insights in linguistic analyses (Sifianou and Bella, 2019). However, the field has focused primarily on English. Although there is a growing body of work on social media practices in Chinese (e.g., Sandel, Ou, Wangchuk, Ju, and Duque, 2019; Ren and Guo, 2020) and Japanese (e.g., Kádár and Fukushima, 2018), many more works are needed. Therefore, based on the above research gaps, the current study aims to investigate requests in Chinese and Japanese on social media. As Chinese is spoken in several countries/regions in Asia and China is a country with a number of main dialects, the way requests are expressed might vary across regions and dialects (Ren, 2018b). For the sake of brevity, in this paper, the term Chinese refers to Mandarin Chinese or its speakers in Chinese Mainland.

In the next section, the literature which is relevant to this study is reviewed. Section 3 introduces the methodology, whilst the findings and discussions 
are presented in sections 4 and 5, respectively. Finally, Section 6 concludes this study.

\section{Literature Review}

Many previous studies have investigated various speech act and politeness realisations in different languages. For example, Tanaka, Spencer-Oatey, and Cray (2008) examined apologies in Japanese and English; and Fukushima and Sifianou (2017) investigated the conceptualisation of politeness in Japanese and Greek, to name but a few. However, speech act realisations in Chinese and Japanese are rarely compared. Only a handful of studies have compared Chinese and Japanese pragmatics (cf. Pan and Kádár, 2011). For example, Haugh and Hinze (2003) investigated the concepts of 'face' and 'politeness' in Chinese, English and Japanese. More specifically, they used metalanguage to describe 'face' in Chinese and English and 'politeness' in English and Japanese. House and Kádár (2020) examined how the second person pronominal T-form is translated in IKEA catalogues in a number of languages, including Chinese and Japanese. Chik and Taboada (2020) analysed structure and rhetorical relations of online book reviews in Chinese, English and Japanese.

In research contrasting many languages, requesting has been frequently investigated (see e.g., Blum-Kulka et al., 1989), as mentioned above. This may be due to the pervasiveness of requests in our daily lives and the fact that making requests is inseparable from the politeness strategies that are used, for example, to avoid threats to the hearer's face and to gain compliance from the hearer (Fukushima, 2000). As Ren (2018a) states, more contrastive research on digital communication is needed to uncover whether certain linguistic and pragmatic strategies and practices result from the affordance of a particular communicative mode or from the particular language. Since the majority of studies on social media practice tend to focus on one language rather than contrasting different languages (see section 1), our investigation can thus address such a call.

Regarding requests in Chinese, many previous studies have argued that directness is preferred. For example, Lee-Wong (1994) explored Chinese requests based on data collected in Mainland China through discourse completion tasks (DCTs). Her findings revealed that Chinese speakers favoured direct, bald-on-record strategies when requesting (see Blum-Kulka et al., 1989 for the coding of request strategies), of which imperatives were the most frequently used. She emphasised that internal mitigators played a crucial role in Chinese requests. By investigating the academic emails that Chinese postgraduates 
sent to university instructors, Zhu (2016) found that the majority (more than $80 \%$ ) of the emails used direct request strategies. Of these, expectation statements (e.g., 'I hope I have the opportunity to ask your advice') ranked first, followed by imperatives. In contrast, a few studies have reported conflicting findings. Additionally, based on DCTs, Zhang (1995) found that Chinese speakers tended to use conventionally indirect strategies most frequently in requests, regardless of status. Query preparatory was the most popular request strategy, followed by imperatives and want/need statements. Grounders were the most frequently used modification.

Recent studies have highlighted that strategy use in Chinese requests is highly contextual. For example, Chen et al. (2013) noted that although the main expressions in Chinese requests belong to conventionally indirect strategies in the form of 'may' or 'can/could' questions, Chinese speakers prefer direct request strategies when interacting with interlocutors of equal status or with those in a close relationship. Likewise, Ren (2018b) observed that when making a request of a higher status interlocutor, Mainland Chinese people favoured the strategy of query preparatory, whereas they used imperatives most frequently when making a request of an equal or a lower status interlocutor. However, they employed various external and internal modifiers to mitigate their direct requests.

The above review indicates that when making a request of an equal status interlocutor, directness is preferred in Chinese (see e.g., Chen et al., 2013; Lee-Wong, 1994; Ren, 2018b). Chinese speakers rely on mitigation devices to encode politeness in requests (Lee-Wong, 1994; Ren, 2018b).

Similar tendencies were found in some previous studies on Japanese requests. Although previous research has stated that the preference in Japanese communication is for indirectness (see e.g., Clancy, 1986; Lebra, 1976; Nakane, 1970; Okabe, 1983; Yamada, 1994, 1997), ${ }^{1}$ direct requests are more preferable than indirect requests, especially among close equals (e.g., Fukushima, 1996, 2000, 2003, 2012, 2014; Rose, 1996). The preference for direct requests, especially among close equals, does not exclude the use of indirect requests in Japanese. Depending on power differences or the degree of imposition, indirect requests, including hints (e.g., Rinnert and Kobayashi, 1999), are also used in Japanese. In keeping with the Chinese, Japanese people also use mitigating devices in their requests. Of these devices, grounders are most frequently used (e.g., Fukushima, 1996, 2009, 2011).

1 Sasshi, or anticipatory inference, contributes to the characterisation of Japanese communication as indirect and plays an important role in Japanese communication (Gudykunst and Nishida, 1993; Yamada, 1997). 
The Japanese university students involved in Fukushima's (2010) study not only preferred a more direct approach than their British counterparts when making requests, but also when evaluating requests. This indicates that, in Japanese, direct requests are not only frequently made, but they are also sometimes preferred.

As previously stated, little research has been conducted into the comparison of requests in Chinese and Japanese. Chen et al. (2013) may have performed the only study that includes a comparison of Chinese and Japanese requests, although the main focus of their study is on investigating the 'East-West divide' in politeness research (Leech, 2007). It should be noted that Chen et al. (2013) did not collect American and Japanese requests. Instead, they replicated Hill et al.'s (1986) methodology to collect Chinese requests and then compared their results with those from the earlier study. The findings indicate that in all three cultural groups, speakers employ request expressions according to the relations they have with the requestees. In terms of the degree of politeness owed to various categories of people, there are fewer differences in China than in Japan. That is, regarding the politeness ranking of different categories of people, Chinese speakers perceive less difference than Japanese speakers. However, we have to be cautious with the findings. First, the Chinese data in Chen et al. (2013) and the Japanese findings they compared with Hill et al. (1986) are two decades apart. This raises a validity issue with the comparison because request strategies and pragmatic performance in certain cultural groups are dynamic and subject to change. Second, only one situation ('borrowing a pen') was examined, which restricted the possibility of generalisation. Third, as acknowledged by Chen et al. (2013), the study was based on self-reported information, which is not the most accurate source of data. Thus, it is important to conduct an empirical study to directly compare requests in Chinese and Japanese.

The Study

\subsection{Research Objectives and Research Questions}

We decided to explore the requests made on social media, as digital communication has substantive consequences for the ways in which people communicate (Ren, 2018a). Young people currently do not use emails very often, particularly when communicating among themselves. Instead, they use social media, and our participants were no exception. In addition, although there have been some studies on email requests between students and faculty members, namely, between status unequals (e.g., Economidou-Kogetsidis, 
2011, 2018; Lorenzo-Dus and Bou-Franch, 2013; Merrison, Wilson, Davies, and Haugh, 2012; Bella and Sifianou, 2012), there are fewer studies on requests between status equals (but see e.g., Fukushima, 2009). Therefore, we focus on requests between status equals. By confining ourselves to requests among status equals, we are able to clearly focus on the similarities and differences between requests in Chinese and Japanese.

The main purpose of the current study is to compare social media requests between equals in Chinese and Japanese. Specifically, this study poses the following research questions:

1) When making a request of their peers via social media, to what extent do Chinese and Japanese speakers differ with respect to the head acts of the requests?

2) When making a request of their peers via social media, to what extent do Chinese and Japanese speakers differ with respect to external request modification?

3) When making a request of their peers via social media, to what extent do Chinese and Japanese speakers differ with respect to internal request modification?

\subsection{Data and Participants}

The data are a natural corpus of 300 social media requests collected from 30 Chinese university students and 304 social media requests collected from 30 Japanese university students. The data consist of authentic requests sent to, or received from, peers, in the sense that none of the requests were elicited for research purposes. The participants were informed that they would each be expected to share 10 requests and that it would be better if they provided both the request and the response, but they were allowed to choose whatever they wanted to share. For the Chinese speakers, the 30 students contributed exactly 10 requests each, resulting in 300 requests. For the Japanese speakers, the contributions were more diverse, ranging from 4 to 35 (mean = $10.13, \mathrm{SD}=6.82$ ), resulting in 304 requests.

The participants were recruited by employing the 'friend of a friend' technique (Milroy, 1987). Thirty Chinese students (15 men and 15 women; age range: $18-23$, mean age: $21.2, \mathrm{SD}=1.27$ ) and 30 Japanese students (10 men and 20 women; age range: $18-22$, mean age: $19.9, \mathrm{SD}=0.87$ ) served as the participants. These two groups of participants were considered to be comparable in terms of their age, occupation and education.

As mentioned above, we investigated requests in Chinese and Japanese among status equals. To guarantee the conformity of the data between Chinese and Japanese, we first asked our participants what the term peers 
meant to them. According to our participants, peers were those who joined the university in the same year. Thus, among peers, the participants were ranked the same in terms of social status. Although social distance may have varied slightly, they were fairly familiar with each other. University students in China and Japan are generally of a similar age when they first enroll. However, some students do not successfully pass their entrance examinations, and therefore enter university a year or so later. In such cases, some students are slightly older than the other students enrolled in the same year, and a senior student can be younger than a junior student. Although age is indeed important in both Chinese and Japanese cultures, the year of college enrolment was considered to be more important than the age of our participants. The students frequently exchanged messages via social media (WeChat in China and LINE in Japan). Thus, we asked our participants to collect request data that they had made to, or received from, their peers via social media. The data were collected from April to July 2019.

\subsection{Data Coding and Analysis}

Employing the coding scheme developed by Blum-Kulka et al. (1989), we discussed and made some modifications to suit both the Chinese and Japanese data, with reference to Ren (2019). Tables 1-3 show the request strategies, external modifications and internal modifications coded in the current study. For the pragmatic strategies that were found in both Chinese and Japanese, Chinese examples are provided first, with Japanese examples following.

TABLE 1 Request strategies

Strategies Examples

Direct requests

Kai men. [Open the door.]

Rimokon motte kite. [Bring me a remote control.]

Conventionally indirect requests

Query preparatory

Neng/keyi/Neng buneng bang wo na kuaidi ma?

[Can/Can't you help me get the parcel?]

Pasokon no tsukaikata oshiete kuremasen ka?

[Can't you show me how to use a computer?]

Non-conventionally indirect requests

Hints

Ni you shang xingqi de biji ma? [Do you have the notes of last week?]

Purinto aru? [Do you have the handout?] 
TABLE 2 External modifications

External modification $\quad$ Examples

\section{Mitigating supportive moves}

Apology

Obtaining a

pre-commitment

Grounder

Imposition minimiser

Preparator

Promise of reward

Onomatopoetic words or emoji

\section{Aggravating supportive moves}

Repetition of the head act

\section{Adjuncts}

Address term

Alerter

Urging

\section{Duibuqi. [I'm sorry.] \\ Sumimasen. [I'm sorry.]}

Neng bang wo ge mang ma? [Can you do me a favour?]

Tanomi ga aru. [I have a favour to ask you.]

Wo tai mang le. [I'm so busy.]

Tokikata ga wakara nai. [I don't know how to solve this.]

Ruguo niyoukong de hua. [If you are free.] Moshi isogashiku nakattara. [If you are not busy.] Ni mang ma? [Are you busy?]

Hima? [Do you have time?]

Qing ni chi dacan. [I will buy you a big meal.] Gasorin dai harau. [I will pay for the petrol.]

Bang wo qiang badianban de. [Please help me buy the ticket for 8:30.] (as a literal repetition of the head act)

Keyi xianzai ma? [Can we do it now?]

Bakusoku² de kaitou onegai shi masu. [Answer me as soon as possible.]

Full names; Given names; Nicknames, etc. (both Chinese and Japanese)

Zai ma? [Are you there?]

Otsukare! [Hi, there! (lit. 'you are tired') ${ }^{3}$ ]

2 Bakusoku (爆速) here belongs to youth language and means intensifying the speed.

3 It is used as an attention getter, particularly among students. 
TABLE 2 External modifications (cont.)

\begin{tabular}{ll} 
External modification & Examples \\
\hline Request for more & Ni shenme shihou keyi? [When can you \\
information & (do that)?] \\
& Doko no gakkou datta kamo oshiete hoshii desu. \\
& [I also want you to let me know which school \\
& you attended.] \\
& Xiexie. [Thank you.] \\
Arigatou. [Thank you.]
\end{tabular}

TABLE 3 Internal modifications

Internal modification

\section{Syntactic downgraders}

Conditional

Interrogative

Lexical/phrasal downgraders

Appealer (tags)

Consultative device

Downtoner/understater

Politeness marker

Subjectiviser
Examples

Ruguo keyi dehua ... [If it is OK ...]

Moshiyokereba ... [If it is OK ...]

Ni ke bu keyi bang wo na kuaidi? [Would or would

you not help me to get the parcel?]

Kawatte itadakukoto deki masu ka? [Could you

replace me?]

Keyi ma? [OK?]; Hao ma?/Hao bu hao? [OK?/OK or not OK?]

Ni kan [you see]

ba/ya (sentence final particle); yixia [a while]; verb reduplication $V(y i) V: k a n$ (yi) kan [have a look] dake [only, just] (Ichibun dake de iikara doitsugo yakushite hoshii) [It is all right with just one sentence, but I want you to translate German.] qing [please]; mafan [trouble]; bang [help] Wo xiang zhidao/wen ... [I want to know/ask ...] 
For some lexical/phrasal internal modifiers that were only observed in the Chinese data, only Chinese examples are given. The authors then coded the Chinese and Japanese data. The authors discussed any uncertain or difficult cases and reached an agreement on the coding.

The data were analysed using the Statistical Package for the Social Sciences (SPSs), version 25. An initial descriptive quantitative analysis was carried out to determine the similarities and differences that existed between the two groups of data. For all statistical analyses, the alpha level (significance level) was set at 0.05 .

\section{$4 \quad$ Findings}

\subsection{Request Strategies}

Table 4 presents the frequency and percentage of request strategies in Chinese and Japanese. It should be noted that there are 300 requests in Chinese and 304 in Japanese. For brevity, since the numbers are so close, we will not remind readers of this fact in every comparison.

As shown in Table 4, both Chinese and Japanese students preferred using direct requests when making requests of their peers on social media $(48.67 \%$ and $54.93 \%$, respectively), followed by conventionally indirect requests (39.67\% and $42.11 \%$, respectively). Compared with Chinese students, Japanese students used more direct and conventionally indirect requests. In contrast, the Chinese students used non-conventionally indirect requests much more frequently than their Japanese counterparts ( $11.67 \%$ and $2.96 \%$, respectively).

TABLE 4 Request strategies in Chinese and Japanese

Request strategy Chinese $(n=300) \quad$ Japanese $(n=304)$

frequency percentage frequency percentage

\begin{tabular}{lrrrr}
\hline Direct & 146 & $48.67 \%$ & 167 & $54.93 \%$ \\
Conventionally indirect & 119 & $39.67 \%$ & 128 & $42.11 \%$ \\
Non-conventionally indirect & 35 & $11.67 \%$ & 9 & $2.96 \%$ \\
Total & 300 & $100.00 \%$ & 304 & $100.00 \%$ \\
\hline
\end{tabular}


Although the two groups had a similar order of preference for the three request strategies, the Chi-square test result showed that the Chinese and Japanese students differed significantly with respect to the request strategy they employed in social media requests (Chi-square $=17.1, \mathrm{df}=2, \mathrm{p}<.0005$ ). A Fisher's exact test indicated that only the difference in non-conventionally indirect requests was significant $(\mathrm{p}<.0005)$ between the two groups.

The following are examples of the three request strategies employed by Chinese and Japanese students.

\section{Direct request}

Example 1. (Chinese)

帮我填个调查问卷吧 Bang wo tian ge diaocha wenjuan ba? (Help me fill out a questionnaire.) [Politeness marker + Direct request + Downtoner]

Example 2. (Japanese)

一ちゃん! 先遇のジェン タース間のブリント見せては しいです
$X X X$ [given name] chan, senshuu no jendaa nyuumon no purinto misete hoshii desu. (xxx, I want you to let me take a look at the handout for Introduction to Gender from last week.)

[Address term + Direct request + Emoji (asking/begging + sweating, showing the requester's feelings, namely, 'Sorry to make this request')]

Conventionally indirect request

Example 3. (Chinese)

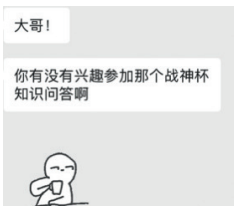

Dage! Niyou meiyou xingqu canjia nage zhanshenbei zhishi wenda a? (Big brother! Are you interested in participating in the Wars Cup knowledge quiz?)

[Address term + Conventionally indirect request + Emoji (drinking coffee/tea and waiting)]

Example 4. (Japanese)

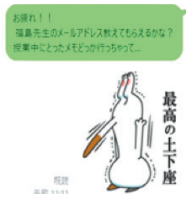

Otsukare! (Hi, there!)

Fukushima sensei no meeru adoresu oshiete moraeru kana? (Can you let me know the email address of Prof. Fukushima?)

Jyugyouchuu ni totta memo dokka icchatte. (I lost the notes that I took during the class.) 
Saikou no dogeza. (Going down on one's hands and knees in the supreme form.)

$[$ Alerter + Conventionally indirect request + Grounder + Emoji ('stamps') (see footnote 6)]

Non-conventionally indirect request

Example 5. (Chinese)

老师说过考啥你还记得吗 Laoshi shuoguo kao sha ni hai jide ma? (Do you still remember what the teacher said about the exam?)

Example 6. (Japanese)

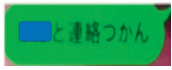

$X X X$ [given name] to renraku tsukan. (I can't get in touch with $\mathrm{Xxx}$.)

\subsection{External Modification}

Table 5 shows the external modification employed by the Chinese and Japanese participants in their requests on social media. Overall, the Japanese participants employed many more external modifiers $(f=549)$ than the Chinese participants $(f=247)$. This difference mainly resulted from the different numbers of mitigating external modifications, since the Japanese participants used 408 mitigating external modifiers, whereas the Chinese participants employed only 113 mitigating external modifiers. Neither the Chinese nor the Japanese participants used aggravating external modifications frequently, as these modifications comprised only $2.83 \%$ and $0.36 \%$ of the total number of external modifications used in each group, respectively. The two groups used similar numbers of adjuncts: 127 for the Chinese participants and 139 for the Japanese participants. However, the percentage of adjuncts is considerably different in the external modifications of the Chinese and Japanese requests. Adjuncts were present in more than half $(51.42 \%)$ of the external modifications in Chinese requests, whereas they were present in approximately a quarter $(25.32 \%)$ of the external modifications in Japanese requests.

We also examined the similarities and differences with respect to individual external modifiers in the requests. For the modifiers that served to mitigate the force of the request, a Fisher's exact test showed that the Japanese participants employed significantly more 'apology' modifiers ( $\mathrm{f}=63$ for Japanese, $\mathrm{f}=6$ for Chinese; $\mathrm{p}<.0005)$, more 'obtaining a pre-commitment' modifiers ( $\mathrm{f}=17$ for Japanese, $f=3$ for Chinese; $p=.002$ ), more 'grounder' modifiers ( $f=133$ for Japanese, $\mathrm{f}=42$ for Chinese; $\mathrm{p}<$.0005), more 'imposition minimiser' modifiers $(\mathrm{f}=60$ for Japanese, $\mathrm{f}=8$ for Chinese; $\mathrm{p}<$.0oo5) and more 'onomatopoetic 
TABLE 5 External modifications in Chinese and Japanese

External modification Chinese (300) Japanese (304)

frequency percentage frequency percentage

\begin{tabular}{lrrrr}
\hline Mitigating & 113 & $45 \cdot 75 \%$ & 408 & $74 \cdot 32 \%$ \\
Apology & 6 & $2.43 \%$ & 63 & $11.48 \%$ \\
Obtaining a pre-commitment & 3 & $1.21 \%$ & 17 & $3.10 \%$ \\
Grounder & 42 & $17.00 \%$ & 133 & $24.23 \%$ \\
Imposition minimiser & 8 & $3.24 \%$ & 60 & $10.93 \%$ \\
Preparator & 36 & $14.57 \%$ & 29 & $5.28 \%$ \\
Promise of reward & 1 & $0.40 \%$ & 1 & $0.18 \%$ \\
Onomatopoetic words or emoji & 17 & $6.88 \%$ & 105 & $19.13 \%$ \\
Aggravating & 7 & $2.83 \%$ & 2 & $0.36 \%$ \\
Repetition of the head act & 3 & $1.21 \%$ & 0 & $0.00 \%$ \\
Urging & 4 & $1.62 \%$ & 2 & $0.36 \%$ \\
Adjuncts & 127 & $51.42 \%$ & 139 & $25 \cdot 32 \%$ \\
Alerter & 26 & $10.53 \%$ & 58 & $10.56 \%$ \\
Address terms & 74 & $29.96 \%$ & 59 & $10.75 \%$ \\
More information & 3 & $1.21 \%$ & 1 & $0.18 \%$ \\
Thanking & 24 & $9.72 \%$ & 21 & $3.83 \%$ \\
Total & 247 & $100 \%$ & 549 & $100 \%$ \\
\hline
\end{tabular}

words or emoji' modifiers ( $\mathrm{f}=105$ for Japanese, $\mathrm{f}=17$ for Chinese; $\mathrm{p}<.0005$ ) than the Chinese participants. In contrast, the Chinese participants employed more 'preparators' than the Japanese participants $(\mathrm{f}=36$ and $\mathrm{f}=29$, respectively), but the difference did not reach a significant level $(p=0.36)$.

With respect to adjuncts, the two groups used similar numbers of 'thanking' adjuncts. The Japanese participants used significantly more 'alerter' adjuncts than the Chinese participants ( $\mathrm{f}=58$ for Japanese and $\mathrm{f}=26$ for Chinese, $\mathrm{p}<$ $0.0005)$. The Chinese participants used more 'address term' adjuncts than the Japanese participants $(\mathrm{f}=74$ and $\mathrm{f}=59$, respectively $)$, but the difference did not reach a significant level $(\mathrm{p}=0.14)$.

\subsection{Internal Modification}

Table 6 presents the internal modifications employed by the Chinese and Japanese participants in their requests on social media. As shown in the table, there is a marked contrast between the two groups with respect to lexical/phrasal internal modifiers. The Chinese participants used each type of 
TABLE 6 Internal modifications in Chinese and Japanese

Internal modification

Chinese (300)

Japanese (304)

frequency percentage frequency percentage

Lexical/Phrasal

Appealer

Consultative device

Downtoner/Understater

Politeness markers

Subjectiviser

Syntactic

Conditional

Interrogative

Total

320
16
5
156
141
2
170
16
154
490

\section{$65.31 \%$}

$3.27 \%$

$1.02 \%$

$31.84 \%$

$28.78 \%$

$0.41 \%$

$34.69 \%$

$3.27 \%$

$31.43 \%$

$100.00 \%$

13

o

o

13

o

o

111

34

77

124
$10.48 \%$

$0.00 \%$

$0.00 \%$

$10.48 \%$

$0.00 \%$

$0.00 \%$

$89.52 \%$

$27.42 \%$

$62.10 \%$

$100.00 \%$

lexical/phrasal modifier, including 'appealers', 'consultative devices', 'downtoners/understaters', 'politeness markers' and 'subjectivisers', resulting in 320 instances of lexical/phrasal internal modification in their requests on social media. In contrast, the Japanese participants only employed 13 instances of 'downtoner/understater' and did not use any other strategy to mitigate the force of their requests internally. Even in the case of 'downtoners/understaters', the Chinese participants used significantly more of these internal modifiers than the Japanese participants $(\mathrm{f}=156$ and $\mathrm{f}=13$, respectively, $\mathrm{p}<0.0005)$.

With respect to the syntactic means used to mitigate the request, the Japanese participants used significantly more conditional sentences than the Chinese participants ( $\mathrm{f}=34$ for Japanese and $\mathrm{f}=16$ for Chinese; $\mathrm{p}=0.01$ ), whereas the Chinese participants used significantly more interrogatives than the Japanese participants ( $\mathrm{f}=154$ and $\mathrm{f}=77$, respectively, $\mathrm{p}<0.0005$ ).

Examples 7-10 showcase both the different and similar ways in which the Chinese and the Japanese participants performed their requests.

Example 7.(Chinese)

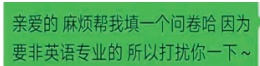

qinaide, mafan bang wo tian yige wenjuan ha, yinwei yao fei yingyu zhuanye de, suoyi darao ni yixia . (Dear, please help me fill out a questionnaire. Because I need a non-English Major participant, I'm bothering you.) [Address term + Politeness marker + Direct request + Downtoner/understater + Grounder] 
Example 8. (Japanese)

おはよ〜

今日寝坊したから、

来週中国語のノート見しても

Ohayo. Kyou nebou shita kara raishuu chuugokugo no nooto mishite.

(Morning. I got up late today. Let me take a look at your notes for Chinese from last week.) [Alerter + Grounder + Direct request + Emoji (crying and begging)]

Example 9. (Chinese)

XXX [given name], jiali meiyou chufangzhi le, ni fang bu fangbian xiake dai yidian huilai?

$X X X$ [given name], there are no tissues in the kitchen. Could you buy some after class? [Address term + Grounder + Conventionally indirect request + Interrogative + Downtoner/understater]

Example 10. (Japanese)

急にラインごんねん 今日の夜取〜 ?

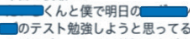

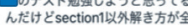
くかからんくて手詰まりなん

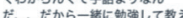

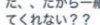

てくれない??

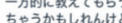

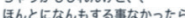
でよいからお前いしたい!
KyUu ni LINE gomen ne. (Sorry for this abrupt contact through LINE.) [Apology + Emoji (asking/begging/ apologising)]

Kyou no yoru hima? (Do you have time this evening?) [Obtaining a pre-commitment] $X X X$ [given name] kun to boku de ashita no $X X X X$ [the name of a professor] no tesuto benkyou shiyou to omotte run dakedo sekushon 1 igai no tokikata ga mattaku wakaran kute tezumari nanda. (Although $\mathrm{xxx}$ and I are going to study for the exam of Xxxx [the name of a professor] tomorrow, we cannot at all solve the problems except those in section 1.) [Grounder]

Dakara issho ni benkyou shite oshiete kurenai?? (So, could you study with us and teach us?) [Interrogative, Conventionally indirect request]

Ippou teki ni oshiete morau youni nacchaukamo shiren kedo. (It may be that you only teach us.)

Hontou ni nanmo surukoto nakattara de yoikara (Only if you do not have anything else to do) [Imposition minimiser]

Onegai shitai. (I ask of you.) [Urging]

As the two direct requests show (examples 7 and 8), there are many situations where both the Chinese and Japanese participants prefer to make their requests 
directly. In example 7 , the Chinese participant employed internal modifiers, including a 'politeness marker' and a 'downtoner/understater', to mitigate his/ her request, whereas the Japanese participant in example 8 used the external modifier 'emoji'. Moreover, the Chinese participant used an 'address term' to begin his/her message, while the Japanese participant used an 'alerter'. However, they both employed a 'grounder' to explain why they needed to make the request. Likewise, for the two conventionally indirect requests (examples 9 and 10), the Chinese participant used an 'address term' and the lexical modifier 'downtoner/understater' to mitigate his/her request in example 9, whereas the Japanese participant used more external modifiers, such as an 'apology', an 'emoji', 'obtaining a pre-commitment' and an 'imposition minimiser' in example 10. Again, both the Chinese and Japanese participants explained the reasons for making their requests (a 'grounder') before fulfilling the request head act in an interrogative and conventionally indirect manner.

\section{Discussion}

This study has investigated the requests made by Chinese and Japanese university students among peers on social media, because, to the best of our knowledge, no such previous studies have been undertaken. The results indicated that the Chinese and Japanese participants displayed more similarities than differences regarding the request strategy that they preferred to use among peers on WeChat and LINE, respectively. Both groups employed direct requests the most frequently, followed by conventionally indirect requests. Non-conventionally indirect requests were used the least frequently by both groups, and particularly so in the case of the Japanese participants.

It is likely that social media communication has evolved into a particular genre that influences an individual's pragmatic performance (see e.g., Page, 2012; Tagg et al., 2017; Ren and Guo, 2020). The reason for non-conventionally indirect requests only being employed infrequently by our participants may be due to the communication channel, namely, social media. It may be more difficult for requestees to infer the intentions of the requesters solely on the basis of messages posted on social media than in face-to-face interactions (see the discussion below). Therefore, such requests need to be explicitly expressed. To a certain extent, this study reflects the benefit of conducting contrastive investigations into pragmatic practices in social media communication or, more generally, digital communication. Since digital communication has critically challenged traditional linguistic findings and theories, it has attracted much attention within our field. However, the majority of studies on digital 
communication focus on only one language, primarily English, although some studies have begun to explore multilingual or translingual practices (Danet and Herring, 2007; Li and Zhu, 2019). Further contrasting explorations are warranted to determine whether new linguistic and pragmatic strategies are the result of the affordances of a particular communicative mode or the result of evolving and emerging practices in certain languages (Ren, 2018a). In addition, it is worth reminding the reader that the requests were made between peers. That is, the absence of authority between the requester and the requestee may have had an impact on the request strategies employed. It is possible that the Chinese and Japanese participants shared similar preferences with respect to request strategies among peers, since they were comparable in many aspects, such as age and education. Moreover, Chinese and Japanese cultures have many core values in common (for example, as mentioned above, age is important in both Chinese and Japanese cultures). After all, traditionally, both Chinese and Japanese cultures have been influenced by Confucianism.

The preference for direct requests among Chinese peers on social media is in line with the findings for Chinese requests in face-to-face communication (Chen et al., 2013; Ren, 2018b; Lee-Wong, 1994) and in email communication (Zhu, 2016). The preference for direct requests among Japanese peers also mirrors the previous findings of Rose (1996) and Fukushima (1996, 2000, 2003, 2012), but differs from other claims in earlier communication studies (e.g., Clancy, 1986; Yamada, 1994, 1997). The two groups were only significantly different with respect to non-conventionally indirect requests, in that the Chinese participants used significantly more hints than the Japanese participants. The living conditions of the students may partly account for this result: namely, all Chinese university students live in dormitories, with four to eight students often living in the same room, ${ }^{4}$ whereas Japanese students mostly live alone in their own apartments or at their parents' homes. Some Japanese students do live in dormitories, but this is not compulsory in Japan. Even when they live in a dormitory, they do not share a room with four to eight other students like the Chinese students. In other words, Chinese university students who share the same dormitory become very familiar with one another, even establishing family-like relationships, whereas Japanese university students, because they do not live in a similar situation, may not become as close to their friends. This difference may have influenced the results to a certain

4 Chinese university students living in the same dormitory often rank themselves according to age as in a family, for example, the eldest is often called 'da ge/jie (eldest brother/sister)', the second eldest 'er ge/jie (second eldest brother/sister)' and the youngest 'xiao di/mei (youngest brother/sister)'. 
extent. The strategies coded as hints by researchers may function as in-group ritual requests for the Chinese participants (Kádár, 2013, 2017). For example, 'Are you going to pick up your package?' just enquires about the receiver's action and does not contain an explicit request. Therefore, such utterances are coded as hints (non-conventionally indirect requests). However, for the students who live together and are very familiar with one another, such enquiries may already have become ritualised as a request to bring back the requester's own parcel. In addition, it is worth noting that non-conventionally indirect requests are only a small proportion of the total number of requests in both groups. Therefore, the differences observed for this strategy do not undermine the overall similarities in how request strategies are employed in Chinese and Japanese social media requests.

With respect to external modifications, the marked contrast between the Chinese and Japanese requests lies in the number of external modifiers that are employed, with the latter $(f=549)$ having twice the number of the former $(\mathrm{f}=247)$. The Japanese participants tried to mitigate the force of their requests by employing more external modifiers than their Chinese counterparts. The three most preferred external modifiers in the Chinese requests were 'address terms', 'grounders' and 'preparators', with those in the Japanese requests being 'grounders', 'onomatopoetic words or emoji' and 'apologies'. Some of these results resonate with the findings of previous studies, for example, with respect to Chinese requests, the frequent use of 'address terms' was at a similar rate to that in Ren $(2018 \mathrm{~b})^{5}$ and 'grounders' were used at similar rates to those in Ren (2018b) and Zhang (1995). In the case of the Japanese findings, the frequent use of grounders resonates with the findings in the previous studies of Fukushima $(1996,2009,2011)$ and the use of 'onomatopoetic words or emoji' agrees with the findings in Fukushima (2008).

Although there were some different preferences when it came to selecting external modifiers, both the Chinese and Japanese participants tended to preempt the risk of having their requests refused, thus saving both the requester's and requestee's face. The popularity of 'preparators' in the Chinese data may be linked to the communication mode. On social media, the interlocutors are generally separate and in different locations. The requester may not know the requestee's current situation. Thus, the requester often initiates questions about whether the potential requestee is busy or does not have time, in order to reduce the possibility of being refused because of these reasons or excuses. The Japanese participants were also aware of the opaque nature of social media communication compared with face-to-face communication; therefore,

5 Ren (2018b) does not distinguish between address terms and alerters. 
they often employed 'onomatopoetic words or emoji' to lighten the communication style (see the discussion below). In addition, they often apologised for any inconvenience that their requests might cause in order to mitigate their requests.

The Japanese participants used over three times as many mitigating external modifications in their social media requests than their Chinese counterparts (408 vs. 113). Mitigating modifiers such as 'apologies', 'grounders', 'imposition minimisers' and 'onomatopoetic words or emoji' were employed significantly more frequently in the Japanese requests than in the Chinese requests. It is said that the Japanese people often 'apologise', even while thanking others (e.g., Coulmas, 1981; Ide, 1998; Ohashi, 2013). In contrast, the Chinese are found to apologise less often (Pan and Kádár, 2011). These contrasting practices may have influenced the more frequent use of 'apology' modifiers by the Japanese participants.

The reason for the Japanese participants' frequent use of 'onomatopoetic words or emoji' may be due to several factors. First, emoji (a Japanese word, lit. 'picture characters') were first developed in Japan. In 1999, the Japanese telephone company Docomo launched the first set of emoji, which was enormously successful, and these emoji were then imitated by competitors (Sampietro, 2019). Emoji have become popular in Japan. Sampietro (2019: 109) states that "[i]n 2009 emoji were standardized internationally by the Unicode consortium and they were integrated into several major operating systems". Second, it is often the case that emoji are used alongside requests in Japanese to show solidarity among equals or to mitigate the force of the request (Fukushima, 2008). Messages without emoji may sometimes sound too harsh, blunt or unfriendly, especially in messages between peers. This is, at least in part, in line with Graham's (2019) contention, namely, that emoji are employed as phatic devices. Third, emoji can replace some words or sentences. According to some of the Japanese participants in this study, they tend to use emoji or so-called 'stamps' 6 when they do not have time or cannot be bothered to write sentences. ${ }^{7}$

The Japanese requests made among peers may sound longer than the Chinese requests in that many external modifiers appear together with the head

6 Emoji are already installed on smart phones, whereas one needs to purchase 'stamps'. Stamps usually contain words or sentences. In this study, stamps are also categorised as 'onomatopoetic words or emoji'.

7 It should be noted that onomatopoetic words and emoji are also quite often used among Chinese university students (Sandel et al., 2019) and function in a similar way to how they are used in Japanese requests, although, in this study, the Chinese participants used fewer emoji than their Japanese counterparts. 
act in the former. In the Japanese requests, mitigating modifiers accounted for approximately three quarters of the total number of external modifications, equalling almost three times the number of adjuncts. In contrast, mitigating modifiers accounted for nearly half of the external modifications in the Chinese requests, which is slightly less than the proportion of adjuncts. The two groups used similar numbers of adjuncts, of which the Japanese participants used significantly more alerters than the Chinese participants, whereas the latter used address terms to start their requests more frequently than the Japanese participants (although the difference did not reach a statistically significant level).

In contrast, the Chinese participants used considerably more lexical/phrasal internal modifiers than the Japanese participants, with the former using approximately 10 times as many as the latter (320 vs. 13). That is, on average, the Chinese participants used more than one lexical/phrasal internal modifier in each request, whereas the probability that a Japanese participant used a lexi$\mathrm{cal} / \mathrm{phrasal}$ internal modifier in a request was less than $5 \%$. The high frequency of internal modification attenuates the illocutionary force in the Chinese direct requests, which plays a crucial role in making the request sound more polite (Ren, 2018b; Lee-Wong, 1994). The Chinese participants used 'politeness markers' and 'downtoners/understaters' frequently, almost one of each in every two requests. In contrast, the Japanese participants only used a total of 13 'downtoners/understaters' in their requests $(\mathrm{f}=304)$. Surprisingly, no politeness markers were employed in the Japanese requests that were made among peers on social media. The popularity of 'downtoners/understaters' and 'politeness markers' in the Chinese requests mirrors what has been previously found. For example, $\mathrm{Su}$ and Ren (2017) found that interrogatives and understaters were two popular modifiers in Chinese requests, followed by politeness markers. These three strategies were also the three most frequently used internal modifiers in the Chinese requests in the current study. With respect to syntactic internal modification, both groups employed the two syntactic means to mitigate requests. The Japanese participants used conditional sentences significantly more frequently than the Chinese participants. The Japanese participants may have tried to show some form of reserved attitude (enryo) (e.g., Ishii, 1984) by their use of conditional sentences. In contrast, the Chinese participants used significantly more interrogatives than the Japanese participants. The high frequency of interrogatives in Chinese was in line with the frequent use of downtoners because sentence final particles in Chinese often serve the function of questioning (Li and Thompson, 1981).

The findings in the current study indicate that the Chinese participants prefer internal modifications in their requests among peers on social media, 
whereas the Japanese participants prefer external modifications. However, if we examine the overall number of modifications, that is, we combine external and internal modifications, we find that the Chinese and Japanese participants employed similar numbers of modifiers to attenuate the force of their requests. The Chinese participants used 737 modifiers (247 external and 490 internal) in the 300 requests, with an average of 2.46 modifiers per request. The Japanese participants used 673 modifiers (549 external and 124 internal) in the 304 requests, with an average of 2.21 modifiers per request.

As indicated by examples 7-10, although the Chinese and Japanese participants differed in respect to their use of external and internal modifications, their request strategy preferences display more similarities than differences. In addition, it is possible that although the realisation of such modifications differs, that is, through either internal or external modification, the perception of politeness/impoliteness created by the overall modification may be similar.

It is possible that direct requests in conjunction with a high number of modifications are the preferred means of realising the speech act of request among peers on social media for both Chinese and Japanese participants. In addition, as Blum-Kulka (1987) notes over three decades ago, (in)directness is not to be equated with politeness. Thus, it is reasonable to argue that (in)directness is not the most appropriate assessment scale for politeness in requests, at least among young status equals on social media. Direct requests with modifications may be perceived as being as polite as, or even more polite than, indirect requests without modifications. Or, it may be that indirect requests have a tendency to sound too polite or ironic/sarcastic when made among peers (see e.g., Blum-Kulka, 1987 for the relationship between indirectness and politeness; Byon, 2006). In such cases, it is unlikely that one can gain compliance from requestees. Moreover, indirectness in one language does not necessarily mean the same thing in another language in terms of compliance with requests (see e.g., Márquez Reiter, 200o). This may be related to linguistic ideologies about directness in different languages, communities of practice or cultures (see e.g., Grainger and Mills, 2016).

\section{6}

\section{Conclusion}

This study investigated the requests made between peers in Chinese on WeChat and Japanese on LINE. The results indicated that both Chinese and Japanese university students preferred direct requests when approaching their peers, followed by conventionally indirect requests. Neither group used nonconventionally indirect requests frequently. As little research has compared 
requests in Chinese and Japanese on social media, this study contributes to the field of contrastive pragmatics and provides more insights to pragmatics and politeness research in these two East Asian languages.

Some issues should be addressed in future studies. First, the closeness between requesters and requestees, the power or authority difference between interlocutors, the degree of imposition of the requested acts and gender (whether one makes requests of a person of the same/different gender) are among these issues. Request strategies and modifications may differ depending on these factors. Second, some differences even exist within the same request strategy depending on the level of formality (informal/formal). For example, in Japanese '... te kuremasen ka?' ('Would you ...?') (which can be categorised as a conventionally indirect request) can have variations, such as '- te kureru?' and '- te kudasaimasen ka?', which differ in terms of their formality. Thus, requests that are categorised as the same strategy can be further analysed from the perspective of formality or style shifting. Third, it is important to investigate whether requests are accepted or rejected. That is, the whole sequence of requests and responses needs to be investigated in future research. Finally, the current study used convenience sampling to investigate the social media requests made by university students. Needless to say, future studies should expand the participant pool and examine requests in other communicative modes.

\section{Notes on Contributors}

Wei Ren is Professor of Applied Linguistics at the School of Foreign Languages, Beihang University, Beijing, China. His research interests include pragmatics and second language acquisition. His recent publications include articles in Applied Linguistics, Assessing Writing, Discourse Context \& Media, ELT Journal, Intercultural Pragmatics, International Journal of Bilingual Education and Bilingualism, Journal of Pragmatics, Pragmatics, and System.

Saeko Fukushima is Professor in the Department of English at Tsuru University in Japan, and a visiting senior research fellow at Hungarian Research Institute for Linguistics (NYTI). Her research interests include cross-cultural pragmatics, interpersonal pragmatics, metapragmatics and politeness. She is the author of Requests and Culture: Politeness in British English and Japanese (2000/2002/2003, Peter Lang) and Metapragmatics of Attentiveness: A Study in Interpersonal and Cross-cultural Pragmatics (2020, Equinox). She has published articles mostly on requests, politeness and attentiveness in major 
international journals. She is a board member of a peer-reviewed academic journal East Asian Pragmatics.

\section{Acknowledgements}

We would like to express our gratitude to the anonymous referees whose comments have helped us to increase the quality of our paper. We are also indebted to Daniel Kadar and Juliane House for their continuous support. All remaining errors are our own.

The second author's research was supported by the Tsuru University Grant-in-Aid for Scientific Research (Juuten ryouiki kenkyuu 2019-2020) and the мтA Momentum (Lendulet) Research Grant (LP2017/5) at Hungarian Research Institute for Linguistics (NYTI).

\section{References}

Barron, Anne. 2008. The structure of requests in Irish English and English English. In: Klaus P. Schneider, and Anne Barron (eds.), Variational Pragmatics: A Focus on Regional Variaties in Pluricentric Languages. Amsterdam: John Benjamins, 35-67.

Bella, Spyridoula, and Maria Sifianou. 2012. Greek student e-mail requests to faculty members. In: Leyre Ruiz de Zarobe, and Yolanda Ruiz de Zarobe (eds.), Speech Acts and Politeness across Language and Cultures. Bern: Peter Lang, 89-113.

Blum-Kulka, Shoshana. 1987. Indirectness and politeness in requests: Same or different? Journal of Pragmatics 11(2): 131-146.

Blum-Kulka, Shoshana, Juliane House, and Gabriele Kasper (eds.). 1989. Cross-cultural Pragmatics: Requests and Apologies. Norwood, NJ: Ablex.

Bou-Franch, Patricia, and Pilar Garcés-Conejos Blitvich. 2019. Analyzing Digital Discourse: New Insights and Future Directions. Switzerland: Palgrave Macmillan.

Brown, Penelope, and Stephen C. Levinson. 1987. Politeness: Some Universals in Language Usage. Cambridge: Cambridge University Press.

Byon, Andrew Sangpil. 2006. The role of linguistic indirectness and honorifics in achieving linguistic politeness in Korean requests. Journal of Politeness Research 2(2): $247-276$.

Chen, Rong, Lin He, and Chunmei Hu. 2013. Chinese requests: In comparison to American and Japanese requests and with reference to the "East-West divide". Journal of Pragmatics 55: 140-161.

Chik, Sonya, and Maite Taboada. 202o. Generic structure and rhetorical relations of online book reviews in English, Japanese and Chinese. Contrastive Pragmatics 1(2): 143-179. 
Clancy, Patricia M. 1986. The acquisition of communicative style in Japanese. In: Bambi B. Schieffelin, and Elinor Ochs (eds.), Language Socialization across Cultures. Cambridge: Cambridge University Press, 213-250.

Coulmas, Florian.1981. "Poison to your soul": Thanks and apologies contrastively viewed. In: Florian Coulmas (ed.), Conversational Routine: Explorations in Standardized Communication Situations and Prepatterned Speech. The Hague: Mouton, 69-91.

Danet, Brenda, and Susan C. Herring. 2007. The Multilingual Internet: Language, Culture, and Communication Online. Oxford: Oxford University Press.

Economidou-Kogetsidis, Maria. 2011. "Please answer me as soon as possible": Pragmatic failure in non-native speakers' e-mail request to faculty. Journal of Pragmatics 43(13): 3193-3215.

Economidou-Kogetsidis, Maria. 2018. "Mr Paul, please inform me accordingly": Address forms, directness and degree of imposition in L2 emails. Pragmatics 28(4): 489-515.

Fukushima, Saeko. 1996. Request Strategies in British English and Japanese. Language Sciences 18(3-4): 671-688.

Fukushima, Saeko. 200o. Requests and Culture: Politeness in British English and Japanese. Bern: Peter Lang.

Fukushima, Saeko. 2003. A cross-cultural study of requests: the case of British and Japanese undergraduates. In: Katarzyna Jaszczolt, and Ken Turner (eds.), Meaning through Language Contrast. Amsterdam: John Benjamins, 263-275.

Fukushima, Saeko. 2008. Pictographs in Japanese email requests. The Tsuru University Graduate School Review 12: 13-29.

Fukushima, Saeko. 2009. Request strategies among equals in Japanese. The Tsuru University Graduate School Review 13: 13-32.

Fukushima, Saeko. 2010. Hearer's aspect in politeness: The case of requests. In: Dingfang Shu, and Ken Turner (eds.), Contrasting Meaning in Languages of the East and West. Oxford: Peter Lang, 103-135.

Fukushima, Saeko. 2011. External mitigation: Supportive moves in Japanese requests. The Tsuru University Graduate School Review 15: 85-101.

Fukushima, Saeko. 2012. Requests in Japanese: A study through e-mail messages. The Tsuru University Graduate School Review 16: 45-63.

Fukushima, Saeko. 2014. (In)directness and (in)formality in Japanese email requests. In: the editorial committee for the research papers celebrating the 5 oth anniversary of the foundation of the Department of English Tsuru University (ed.), Linguistics, Literature and Beyond: A Collection of Research Papers Celebrating the 5oth Anniversary of the Foundation of the Department of English, Tsuru University. Tokyo: Hituzi Shobo, 3-27.

Fukushima, Saeko, and Maria Sifianou. 2017. Conceptualizing politeness in Japanese and Greek. Intercultural Pragmatics 17(4): 522-555. 
Graham, Sage L. 2019. A wink and a nod: The role of emojis in forming digital communities. Multilingua 38(4): 377-400.

Grainger, Karen, and Sara Mills. 2016. Directness and Indirectness across Cultures. Basingstoke: Palgrave.

Gudykunst, William B., and Tsukasa Nishida. 1993. Interpersonal and intergroup communication in Japan and the United States. In: William B. Gudykunst (ed.), Communication in Japan and the United States. Albany: State University of New York Press, 149-214.

Haugh, Michael, and Carl Hinze. 2003. A metalinguistic approach to deconstructing the concepts of 'face' and 'politeness' in Chinese, English and Japanese. Journal of Pragmatics 35(10-11): 1581-1611.

Hill, Bevery, Sachiko Ide, Shoko Ikuta, Akiko Kawasaki, and Tsunao Ogino. 1986. Universals of linguistic politeness: quantitative evidence from Japanese and American English. Journal of Pragmatics 10(3): 347-371.

Ide, Risako. 1998. 'Sorry for your kindness': Japanese interactional ritual in public discourse. Journal of Pragmatics 29(5): 509-529.

Ishii, Satoshi. 1984. Enryo-sasshi communication: A key to understanding Japanese interpersonal relations. Cross Currents 11(1): 49-58.

Kádár, Dániel Z. 2013. Relational Rituals and Communication: Ritual Interaction in Groups. Basingstoke: Palgrave Macmillan.

Kádár, Dániel Z. 2017. Politeness, Impoliteness and Ritual. Cambridge: Cambridge University Press.

Kádár, Dániel Z., and Saeko Fukushima. 2018. The meta-conventionalisation and moral order of e-practices: A Japanese case study. Internet Pragmatics 1(2):352-378.

Lebra, Takie Sugiyama. 1976. Japanese Patterns of Behavior. Honolulu: University of Hawaii Press.

Lee-Wong, Song Mei. 1994. Imperatives in requests: direct or impolite - observations from Chinese. Pragmatics 4(4): 491-515.

Leech, Geoffrey. 2007. Politeness: is there an East-West divide? Journal of Politeness Research 3(2): 167-206.

Li, Charles N., and Sandra A. Thompson. 1981. Mandarin Chinese: A Functional Reference Grammar. Berkeley: University of California Press.

Li, Wei, and Hua Zhu. 2019. Tranßcripting: playful subversion with Chinese characters. International Journal of Multilingualism: 1-17.

Lorenzo-Dus, Nuria, and Patricia Bou-Franch. 2013. A cross-cultural investigation of email communication in Peninsular Spanish and British English: The role of (in)formality and (in)directness. Pragmatics and Society 4(1): 1-25.

Márquez Reiter, Rosina. 200o. Linguistic Politeness in Britain and Uruguay: A Contrastive Study of Requests and Apologies. Amsterdam: John Benjamins. 
Merrison, Andrew John, Jack J. Wilson, Bethan L. Davies, and Michael Haugh. 2012. Getting stuff done: Comparing e-mail requests from students in higher education in Britain and Australia. Journal of Pragmatics 44(9): 1077-1098.

Milroy, Lesley. 1987. Language and Social Networks. 2nd ed. Oxford: Blackwell.

Nakane, Chie. 1970. Japanese Society. Berkley: University of California Press.

Ogiermann, Eva, and Spyridoula Bella. 2020. An interlanguage study of request perspective: Evidence from German, Greek, Polish and Russian learners of English. Contrastive Pragmatics 1(2): 180-209.

Ohashi, Jun. 2013. Thanking and Politeness in Japanese: Balancing Acts in Interaction. Basingstoke: Palgrave Macmillan.

Okabe, Roichi. 1983. Cultural assumptions of East and West: Japan and the United States. In: William B. Gudykunst (ed.), Intercultural Communication Theory: Current Perspectives. Beverly Hills: Sage, 21-44.

Page, Ruth. 2012. Stories and Social Media: Identities and Interaction. New York: Routledge.

Pan, Yuling, and Dániel Z. Kádár. 2011. Politeness in Historical and Contemporary Chinese. London: Continuum.

Ren, Wei. 2018a. Exploring Chinese digital communication. Discourse, Context and Media 26: 1-4.

Ren, Wei. 2018b. Variational Pragmatics in Chinese requests. Wai Guo Yu (Journal of Foreign Languages) 41(4): 66-75.

Ren, Wei. 2019. Pragmatic development of Chinese during study abroad: A crosssectional study of learner requests. Journal of Pragmatics 146: 137-149.

Ren, Wei, and Yaping Guo. 2020. Self-praise on Chinese social networking sites. Journal of Pragmatics 169: 179-189.

Rinnert, Carol, and Hiroe Kobayashi. 1999. Requestive hints in Japanese and English. Journal of Pragmatics 39(9): 1173-1201.

Rose, Kenneth R. 1996. Japanese, American English, and directness: More than stereotypes. JALT Journal 18(1): 67-8o.

Rue, Yong-Ju, and Grace Qiao Zhang. 2008. Request Strategies: A Comparative Study in Mandarin Chinese and Korean. Amsterdam: John Benjamins.

Sampietro, Agnese. 2019. Emoji and rapport management in Spanish WhatsApp chats. Journal of Pragmatics 143: 109-120.

Sandel, Todd L., Chuyue Ou, Dorji Wangchuk, Bei Ju, and Miguel Duque. 2019. Unpacking and describing interaction on Chinese WeChat: A methodological approach. Journal of Pragmatics 143: 228-241.

Schauer, Gila A. 2009. Interlanguage Pragmatic Development: The Study Abroad Context. London: Continuum. 
Sifianou, Maria, and Spyridoula Bella. 2019. Twitter, politeness, self-presentation. In: Patricia Bou-Franch, and Pilar Garcés-Conejos Blitvich (eds.), Analyzing Digital Discourse: New Insights and Future Directions. Switzerland: Palgrave Macmillan, 341-365.

$\mathrm{Su}$, Yunwen, and Wei Ren. 2017. Developing L2 pragmatic competence in Mandarin Chinese: Sequential realization of requests. Foreign Language Annals $5 \mathrm{O}(2): 433-457$. Tagg, Caroline, Philip Seargeant, and Amy Aisha Brown. 2017. Taking Offence on Social Media: Conviviality and Communication on Facebook. Switzerland: Palgrave Macmillan.

Tanaka, Noriko, Helen Spencer-Oatey, and Ellen Cray. 2008. Apologies in Japanese and English. In: Helen Spencer-Oatey (ed.), Culturally Speaking: Culture, Communication and Politeness Theory. London: Continuum, 73-94.

Woodfield, Helen, and Maria Economidou-Kogetsidis. 2012. Modification in interlanguage requests. In: Maria Economidou-Kogetsidis, and Helen Woodfield (eds.), Interlanguage Request Modification. Amsterdam: John Benjamins, 1-8.

Yamada, Haru. 1994. Talk-distancing in Japanese meetings. Journal of Asian Pacific Communication 5: 19-36.

Yamada, Haru. 1997. Different Games, Different Rules. Oxford: Oxford University Press.

Yeung, Lorrita Ngor-to. 1997. Polite requests in English and Chinese business correspondence in Hong Kong. Journal of Pragmatics 27(4): 505-522.

Yeung, Lorrita Ngor-to. 200o. The question of Chinese indirectness: A comparison of Chinese and English participative decision-making discourse. Multilingua 19(3): 221-264.

Zhang, Yanyin. 1995. Strategies in Chinese requesting. In: Gabriele Kasper (ed.), Pragmatics of Chinese as Native and Target Language. Honolulu, Hawai'i: University of Hawai'i, Second Language Teaching \& Curriculum Center, 23-67.

Zhu, Wuhan. 2016. A cross-cultural pragmatic study of rapport-management strategies in Chinese and English academic upward request emails. Language and Intercultural Communication 17(2): 210-228. 